\title{
Step towards Sustainable Drilling Operations by Turning Waste into Value A Case Study of Oil \& Gas Company
}

\author{
${ }^{1}$ CH. Rama Krushna Chary, ${ }^{2}$ Mohammad Al-Mulla
}

\begin{abstract}
This paper describes the need for the latest state-of-art technology i.e. Indirect Thermal Treatment Technology to adopt, salient features of the indirect thermal treatment technology, key challenges in collection of fresh OBM cuttings from Drilling Rigs and its treatment $\&$ disposal. It also brief the tangible and in-tangible benefits.
\end{abstract}

Keywords — Drilling, Waste, Oil, Gas.

\section{KOC INTRODUCTION}

The Anglo-Persian Oil Company, now known as BP (British Petroleum) and Gulf Oil Corporation, now known as Chevron, established Kuwait Oil Company in 1934.

In 1975, the Kuwait Government took $100 \%$ control over Kuwait Oil Company, and by 1980, the Kuwait Petroleum Corporation was established to bring all state owned oil companies under one entity. KOC continues to live up to its stated mission of exploring, developing and producing Kuwait's hydrocarbon resources for its customers around the world in a way that is environmentally sound and economically viable.

Since its inception, KOC's activities have included exploration operations, onshore and offshore surveys, drilling of test wells and the development of producing wells in addition to crude and natural gas exploration.

As part of the company strategic objective, the company operating with Rig Fleet of 120 Drilling \& Work over Rigs for on-shore Operations. The company uses Oil Based Mud in drilling operations and generates huge quantities of oil based mud (OBM) drill cuttings. The OBM drilling cuttings are toxic, due to PAH (Poly Aromatic Hydrocarbon) content of diesel, the base fluid of oil base mud. PAH consists of toxic priority pollutants. Diesel typically contains 5 to $10 \%$ PAH and falls under hazardous waste category.

In order to move towards sustainable drilling operations and as part of KOC's strategic objective of "Realizing Value from Technology" the Drilling \& Technology (D\&T) Directorate, KOC established OBM Cuttings Treatment Plants at North Kuwait \& Waste Kuwait oil fields. The latest state-of-art technology (i.e. Indirect Thermal Treatment Technology) adopted in establishing these treatment plants with a capacity

\footnotetext{
${ }^{1}$ Senior Environment Engineer, HSE D\&T Team, Kuwait Oil Company

${ }^{2}$ Environment Engineer, HSE D\&T Team, Kuwait Oil Company
}

of 26000 MT / year first time in the State of Kuwait.

\section{SELECTION OF TECHNOLOGY}

A Technology Review Committee was established to identify the state -of-art technology for adopting to treat OBM drill cuttings. The committee studied the best available technologies (BAT) and visited the OBM Cuttings treatment plant in Gulf Cooperation Council (GCC) region to understand the pros and cons of the existing plants in the region. Upon detailed study of various technologies, considering the Kuwait environment conditions and KOC's Zero discharge concept, the technology review committee has selected the indirect thermal desorption technology to treat the OBM Drill cuttings. The Indirect thermal desorption technology provides indirect and controlled heating to separate hydrocarbons undestroyed.

\section{SALIENT FEATURES OF THIS TECHNOLOGY}

The following are key salient features of this technology:

$\checkmark$ Indirect Thermal Desorption is a remediation technology designed to separate the organic constituents from a waste stream in such a manner that they are preserved for collection and recycling.

$\checkmark$ Heat is applied 'indirectly' in that the feed material does not make direct contact with combustion gases. Alternately, heat is transferred from a furnace situated around a long rotating drum to the feed material isolated inside.

$\checkmark$ Indirect heat combined with an inert atmosphere inside the rotary drum prevents any oxidation of the hydrocarbon constituents of the feed material.

$\checkmark$ Hydrocarbons are simply converted to a gas phase where they are separated from the solids through and induced draft. This process gas is routed to the Vapor Recovery Unit (VRU) where it is condensed and collected for recycling.

$\checkmark$ This process renders the feed material non-hazardous, with its organic portions removed, while still preserving the hydrocarbons for collection and recycling.

\section{Collection, TreatMent \& Disposal PROCESS}

The Company's ATDU equipment is described with the main focus being on the Oil Based Mud Drill Cuttings processing. This innovative technology is based on an Indirectheated rotary desorbed system, which employs the use of an oxygen-deficient atmosphere while desorbing / separating volatile and semi-volatile organic compounds from the solids. 
Unlike direct-flame fired systems, which create oxygen rich, environmentally harmful atmosphere, an ATDU system virtually eliminates oxidation and the formation of hazardous compounds. When processing the above streams, typical ATDU plant is composed of several major subsystems that work together in concert. These include (1) feed unit, (2) the indirectly heated rotary drum, (3) treated solids cooling unit, (4) vapor recovery unit, (5) primary water treatment unit made up of oil water separator, (6) and central process controls.

\section{A. Collection}

The main objective of this plant is to perform the drilling operations environment friendly by avoiding the intermediate oil based mud (OBM) drill cuttings storage at drilling rigs and treat the weathered Oil Based Mud (OBM) drill cuttings. The fresh OBM drill cuttings are being collected directly from Drilling Rig to specially designed skips. Theses skips transferred to centralized OBM drill cuttings treatment plant in coordination with drilling rig. Weathered OBM drill cuttings are being collected and transported to OBM drill cuttings plant.

\section{B. Treatment \& Disposal}

Oil based mud drill cuttings are loaded into the feed hopper using a front-end loader. As material is discharged from the hopper it travels via conveyor before reaching to the inlet of the ATDU. En-route the material travels over a belt scale where the feed rate to the ATDU is monitored and adjusted as necessary. The ATDU feed rate is controlled by adjusting the speed of the rotation of the screw-auger system in the feed hopper bottom while all other conveying components operate at constant speed. The feed material undergoes the pretreatment preparation to assure required material conveying and good thermal treatment.

The primary function of the indirectly heated rotary drum is to vaporize the hydrocarbon contaminants and the moisture from the incoming OBM drill cuttings. The indirect heated drum is the heart of the system. It is fabricated with heat and corrosion resistant low nickel alloy for design furnace service temperatures ranging in $800^{\circ} \mathrm{C}-1,200^{\circ} \mathrm{C}$. The rotary drum that is heated from outside while inside a stationary furnace where several burners provide the necessary process heat. As the drum shell is heated the energy is transferred to the contaminated feed material inside the rotary drum through conduction. The material inside are also heated through radiation from the rotary drum's interior shell surface. The rotary drum shell material and the furnace burner capacity are designed to elevated material temperature up to $500^{\circ} \mathrm{C}-600^{\circ} \mathrm{C}$, although these higher operating temperature ranges are rarely necessary for material processing under normal circumstance. By having the burners located inside the furnace the contaminated materials inside the rotary drum do not come in contact with the products of combustion from the burners. The drum's material inlet and discharge are controlled via two airlocks designed to minimize air (oxygen) leakage into the drum. The inlet and discharge end of the rotary drum are equipped with custom designed seals to prevent air leakage. The contaminated material travel time through the rotary drum is controlled by the slope of the unit, number and location of the internal lifters and the rotational speed of the rotary drum. Typically the drum slope and the position and number of lifters are fixed; the rotational speed of the drum is the key feature that controls the retention time of the contaminated material inside the rotary drum. The required retention time inside the rotary drum to achieve any given cleanup goal is highly dependent on the free and bound moisture content of the waste material, solid's physical characteristics such as particle size distribution, type of organic and inorganic compounds present in the waste stream and the vapor pressure of the hydrocarbons. During the treatment process as the oily sludge or drill cuttings travel through the rotary drum the hydrocarbons and water undergo evaporation (desorption) process while generating a very dry and contaminant free solid stream.

The desorbed vapors are transported from the rotary drum into the system's Vapor Recovery Unit (VRU). The main function of the Vapor Recovery Unit (VRU) is to condense and recover the desorbed hydrocarbons, water vapor and the solid particles present in the gas stream exiting the rotary drum. The VRU includes several main components including dry dust collector, quench section, venturi scrubber, separator, mist eliminator section, induced draft fan and condenser. The dry dust collector (cyclone) removes the coarse particles from the gas stream to minimize solids loading on the VRU. Once the gases leave the cyclone they enter the quench section where the gas stream is cooled by direct contact with finely atomized water droplets. As the gas temperature begins to cool down the majority of the hydrocarbons begin to condense out by the time gases leave the quench section. The VRU is equipped with an integrated variable throat venture scrubber for removal of the fine solid particles from the gas stream entering the VRU. The dust laden gas stream and the process water collide, dispersing the liquid into droplets that the particles impact and become entrapped within. These droplets containing the fine solid particles are removed from the gas stream in a horizontal cyclonic separator downstream of the venturi. This venturi is designed with an adjustable throat to maintain the desired pressure drop across the throat as the gas volume changes. This feature assures that the same particulate removal efficiency is maintained as operating parameters change in the system. 


\section{PROCESS FLOW DIAGRAM}

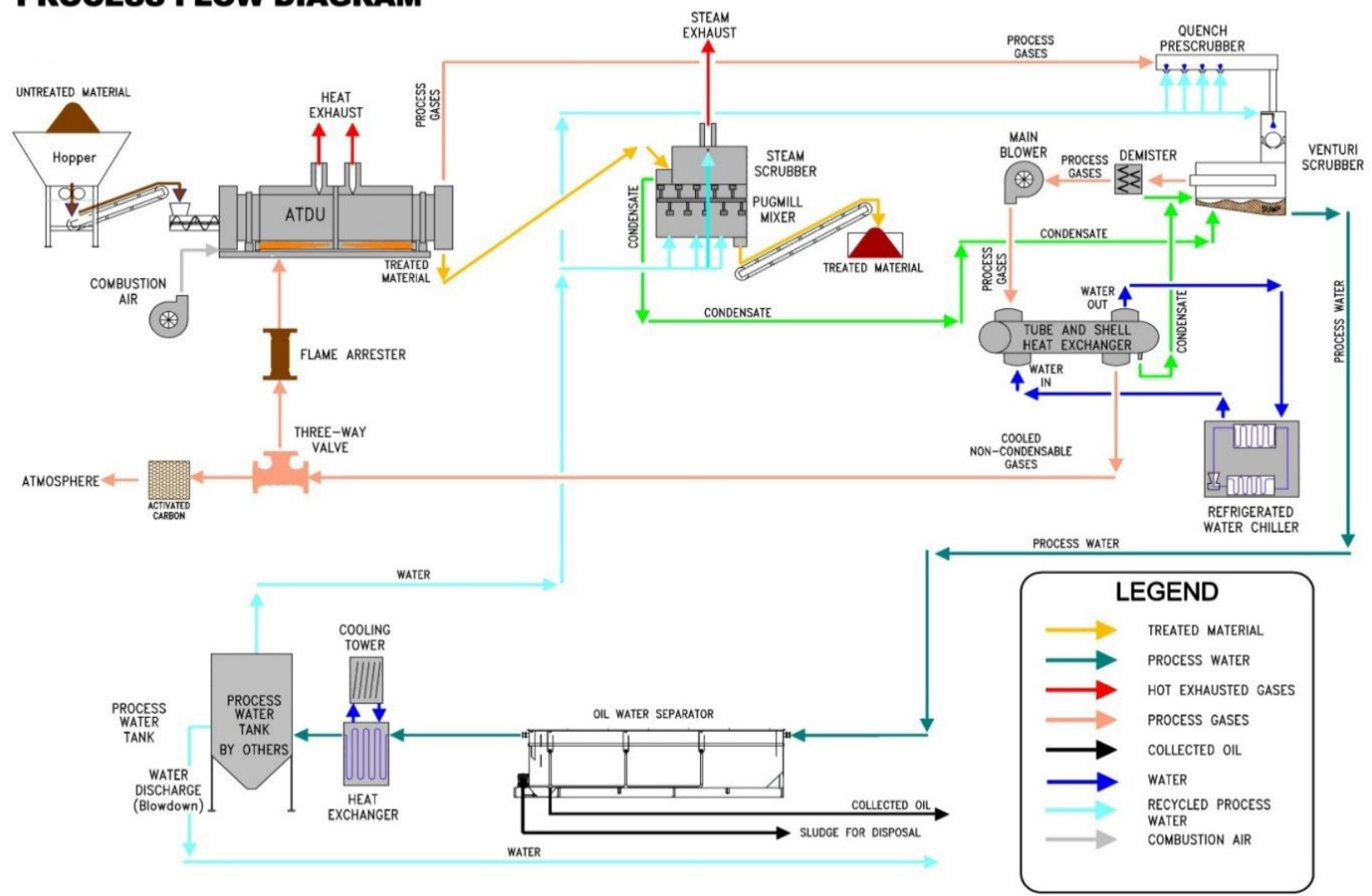

Typical Anaerobic Thermal Desorption Unit (ATDU) Layout (Source: RLC Technologies, Inc.)

The gaseous effluents exiting the cyclonic separator pass through two mist eliminators to remove entrained water droplets before reaching the system ID fan. The process ID fan is equipped with a variable speed controlled drive for sufficient draft through the system while continuously pulling the vapors through and our of the rotary drum, cyclone, separator and the venturi scrubber and then pushing these vapors through the condenser, the flame arrestor and activated carbon bed. Once the gases reach the condenser (indirect heat exchanger) their temperature is dropped to less than $10^{\circ} \mathrm{C}$ to promote removal of the residual hydrocarbon vapors (the lighter hydrocarbons) from the gas stream. Once the gases leave the condenser they travel through a flame arrester before being discharged into an activated carbon bed for final polishing prior to atmospheric discharge.

The condensates, residual fines/sediments and the water collected inside the VRU are treated in an above ground API type primary oil water separator. Depending on the material being processed by the ATDU the separator can produce water that has sediments and oil concentrations in the range of approximately $50-200 \mathrm{mg} / \mathrm{liter}$. The API separator is a gravity separation device that works on the principle of Stokes Law which defines the rise velocity of an oil particle based on its density and size. The oil droplets float to the top and the sediments settle in the bottom of the separator tank. The recovered oil is collected using a stationary skimmer. The collected oil is continuously pumped into an above ground storage tank. The recovered sediments/sludge is pumped from the separator using pneumatic pump and is recycled back into the ATDU process. Once the oil and suspended solids are removed from the influent in the API separator, the middle phase, water, is then pumped out to onsite storage tank for recycling. The entire ATDU plant is centrally controlled using traditional microprocessor based components personal computer (PC) windows based process control software.

\section{Key ChaLLENGE}

We had a biggest challenge to collect the fresh Oil Based Mud (OBM) drill cuttings from drilling rig as the rigs have already pre-designed OBM drill cuttings discharge mechanism were not matching the need of OBM drill cuttings skips. In order to overcome this challenge, we have modified the OBM drill cuttings discharge systems at drilling rigs and also the OBM cuttings collection skips.

\section{TANGIBLE AND IN-TANGIBLE BENEFITS}

The following are the key tangible and in-tangible benefits:

$\checkmark$ Detoxifying the OBM drill cuttings: The treatment plant commissioned in 2015. During this period, treatment plant treated OBM drill cuttings an average 2110 MT per month, collected from 12 weathered OBM cuttings pits and fresh OBM cuttings from 9 Drilling Rigs.

$\checkmark$ Recovered Oil: Recovered oil is being re-used in the ATDU plant as a fuel and it can also be used for kick-off well fluids, stimulation, cleaning of wells and for fresh oil-based 
mud preparation. The plant benefits financially as well by enhancing the corporate image by turning waste into value.

$\checkmark$ Recovered Water: Recovered water reused to moisturize treated drilling cuttings and hydrate treated soils.

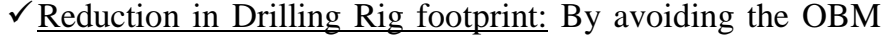
drill cuttings intermediate storage at Drilling Rig, it is helping to reduce the Drilling Rig footprint.

$\checkmark$ Environmentally friendly nature: This technology eliminates the need for land disposal or incineration and meets or exceeds the most stringent clean up criteria. The closed system design reduces atmospheric emissions. Hydrocarbons are separated and recovered, not burnt and released to the atmosphere as greenhouse gases.

$\checkmark$ Waste minimization/ recycling: The non-destructive nature of the process allows wastes to be converted into useful products. It can produce a product with commercial value while reducing and de-listing a hazardous waste stream.

$\checkmark$ Large treatment capability: Basically any compound, organic or inorganic that could be converted to a higher volatile substance and whose boiling point is reachable using our equipment can be removed from a stable matrix and further recycled.

$\checkmark$ Low maintenance design: This special design, additions, and provisions enable the equipment to operate successfully with minimum required maintenance. Abrasive materials such as those found in drill cuttings do not impart wear from friction as is common with other thermal treatment systems.

$\checkmark$ Mobility/ Emergency response: This plant can be easy placed on trailers and transported to remote sites. With the quick electrical disconnects provided the plant allow easy mobilization and demobilization.

$\checkmark$ Cost effectiveness: Transforming a waste to a product that has commercial value, low maintenance design, high quality components, stable and reliable operations, and mobility are all benefits that enable to operate in a most cost-effective way.

\section{CONCLUSION}

The ATDU process offers a unique opportunity where the oily waste material can be processed while not only separating the hydrocarbons and generating a clean reusable solid but it also recovers hydrocarbons for beneficial recycling. The recovered oil can be recycled back into the refining process, back to drilling mud formulation, or cleaned and used to fire the ATDU burners or sold as fuel. The treatment plant benefits financially as well as enhance the corporate image by turning waste in to value towards sustainable drilling operation.

\section{REFERENCES}

[1] Kuwait Oil Company Annual Report 2015-16, http://www.kockw.com/sites/EN/Annual\%20Reports/20152016\%20English.pdf

[2] Separation and recovery of oil from oily waste materials using anaerobic thermal desorption unit technology, RLC Technologies, Inc., https://www.rlctechnologies.com/sg_userfiles/RLC_Technologies_-

_Indirect_Thermal_Desorption.pdf

\section{About Authors}

Mr. CH. Rama Krushna Chary is holding Bachelor of Technology in Chemical Engineering Master of Business Administration with more than 16 years of experience in the Oil \& Gas, Refinery, Consultancy and Chemical sectors. He is a lead auditor for ISO 14001, Internal auditor for ISO 50001, OHSAS 18001 \& ISO 9001 and certified $\mathrm{H} 2 \mathrm{~S}$ Awareness train the trainer. Present working as a Senior Environment Engineer, HSE (D\&T) Team, KOC. Apart from his professional service, he has been volunteering American Society of Safety Engineers (ASSE), USA and United Nations Volunteer (UNV) Program.

Received Kuwait Oil Company (KOC) CEO HSSE Award for three consecutive years from 2013 to 2015. Safety Professional of the Year awards 2017, 2016 and 2016 from ASSE Global Region, ASSE EPS, USA and Kuwait Chapter respectively and Distinguished Young Alumni Public Service Award (DYAPSA) 2016 from National Institute of Technology (NIT), Warangal, India. He has presented many technical Papers at various National and International HSE Conferences and his articles published in national and international magazines.

Mr. Mohammad Al-Mulla (co-author) is holding Bachelor of Science in Environmental science and Master of Business Administration (MBA) from Oregon State University. Worked at Kuwait Oil Company for more than 6 years in HSE drilling operations. Also worked as group planning coordinator and liaising with Kuwait EPA to ensure company compliance with State regulations.

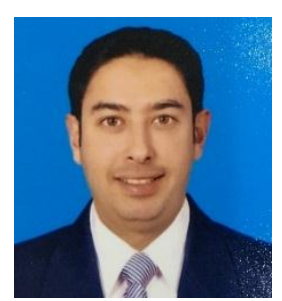

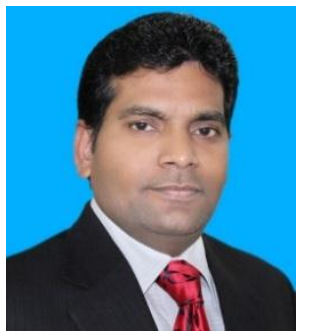

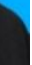

